\title{
MONTAGEM E AVALIAÇÃO DE REATOR DE LABORATÓRIO PARA TRATAMEN- TO BIOLÓGICO DE EFLUENTE TÊXTIL NO SISTEMA LAB (LODOS ATIVADOS POR BATELADA)
}

\section{IMPLEMENTATION AND EVALUATION OF A LABORATORY SCALE BIOLOGICAL REACTOR FOR THE TREATMENT OF TEXTILE WASTEWATER WITH TECHNOLO- GIES AND TECHNIQUES OF SEQUENCING BATCH REACTORS (SBR).}

Fecha de Recepção: Outubro 25 / 2006

Fecha de Aprovação: Novembro 27 / 2006
Prof. MSc Álvaro Chávez Porras

Prof. Dr. Ricardo de Lima Isaac

RESUMO: O trabalho preparou em escala de laboratório o reator biológico, do sistema de Lodos Ativados por Batelada ( $L A B)$, e avaliou o desempenho no tratamento de efluente de indústria têxtil. A pesquisa desenvolveu-se nos laboratórios de Saneamento e Protótipos do Departamento de Saneamento e Ambiente, Faculdade de Engenharia Civil, Universidade Estadual de Campinas. Quanto à fase líquida (despejo), no reator biológico após inoculação descrita neste estudo, avaliou-se a eficiência do sistema LAB nos parâmetros: SST (sólidos suspensos totais) da Serie de Sólidos, Cor ADMI (medição do valor para efluentes de origem têxtil), Demanda Química de Oxigênio (DQO) e Carbono Orgânico Dissolvido (COD). No sistema conseguiu-se uma eficiência dos parâmetros na faixa de 60 a $70 \%$.

PALAVRAS CHAVES: Efluentes têxteis, lodos ativados por batelada (LAB).

ABSTRACT: This work deals with the development and implementation at laboratory scale of a methodology for the treatment of wastewater from a textile factory, using Sequencing Batch Reactors (SBR) -and activated sludge process based on biological reactors-- and the evaluation of its efficiency. To verify the efficiency of the proposed method (or process), the following parameters were evaluated, TSS (Total Suspended Solids), Color ADMI, COD (Chemical Oxygen Demand) and DOC (Dissolved Organic Carbon). The results indicate efficiencies in the range 60 to $70 \%$ for each one of the parameters considered in this study. KEYWORDS: Wastewater, textile industry, biological treatment, SBR. 


\section{INTRODUÇÃO}

Lançar efluentes industriais e esgotos sanitários sem tratamento nos corpos de água é uma prática que gera alto grau de contaminação dos mananciais. Entre as indústrias geradoras de grande quantidade de contaminantes está a indústria têxtil, a qual engloba uma variedade de processos e empresas gerando diferentes efluentes e resíduos sólidos perigosos; particularmente, esta prática afeta consideravelmente ou mata a vida aquática, evitando a penetração de luz, impedindo a fotossíntese, elevando os valores de salinidade (alta condutividade) e limitando seu uso na agricultura.

$\mathrm{Na}$ indústria, os processos caracterizam-se pelo consumo intensivo de água, com operações descontínuas no processo produtivo. No Brasil, o consumo de água varia na faixa de 40 a 290 Litros de água por kg de material processado; esta indústria usa 20 t/ano de corantes, dos quais cerca de $20 \%$ são descartados em efluentes para serem tratados e/ou lançados nos corpos d’água.

Tentando avaliar um tratamento para estes despejos, de efluente de indústria têxtil, desenvolveu-se uma pesquisa nos laboratórios de Saneamento e Protótipos do Departamento de Saneamento e Ambiente, Faculdade de Engenharia Civil, Universidade Estadual de Campinas, UNICAMP, onde se preparou em escala de bancada de laboratório o reator biológico, do sistema de Lodos Ativados por Batelada (LAB), e avaliou seu desempenho.

Quanto à fase líquida ou despejo, no reator biológico após inoculação (descrita no estudo), avaliou-se a eficiência do sistema LAB nos parâmetros:

- SST (sólidos suspensos totais) da Serie de Sólidos,

- Cor ADMI (medição do valor para efluentes de origem têxtil),

- Demanda Química de Oxigênio (DQO) e

- Carbono Orgânico Dissolvido (COD).

No final da fase de avaliações, no sistema conseguiu- se uma eficiência dos quatro parâmetros na faixa de 60 a $70 \%$.

\section{REVISÃO BIBLIOGRÁFICA}

Segundo PÔRTO (2002), FERREIRE da SILVA (2004), SALES et al (2003), USEPA (1997), SOUZA et al (2005), YAMAGUTI et al (2005) e FUKUNAGA (2003), todos os resíduos da industrial têxtil, neste caso, efluentes líquidos finais, variam em suas características, nos corantes empregados nos processos. $O$ despejo gerado é pouco homogêneo, com alta variabilidade de vazão, $\mathrm{pH}$ e de carga orgânica, além de sua pouca biodegradabilidade, presença de sais dissolvidos, corantes sintéticos, substâncias tóxicas, metais, detergentes, óleos e graxas.

Para BRESAOLA \& CANTELLI (2001), e PÔRTO (2002), para atender à legislação, principalmente os padrões legais de emissão e de qualidade, a indústria têxtil tem como processos de tratamento mais utilizados, os biológicos; um dos mas usados é o processo de Lodos Ativados de Fluxo Intermitente ou Lodos Ativados por Batelada (LAB). Estes são processos aeróbios de tratamento biológico que usam as reações metabólicas dos microrganismos para produzir um efluente de qualidade pela oxidação e conversão da matéria orgânica em dióxido de carbono, água e biosólidos (lodo). O oxigênio introduzido permitirá a vida de microrganismos em altas concentrações e as colônias formadas usarão os poluentes como alimento e os incorporarão em seu metabolismo, removendo as partículas dissolvidas e não sedimentáveis do despejo; na remoção dos poluentes podem trabalhar em todos os tamanhos de partículas (em suspensão ou dissolvidas) de uma maneira efetiva. São bastante usados no tratamento de águas residuárias com alta carga orgânica e para tratamento de despejos industrial, alem de serem muito simples de operar; sendo um método efetivo na relação custo - beneficio, HELMREICH et al (2000) e NETO \& SILVA (2005). No caso de despejo têxtil, o processo biológico con- 
siste numa oxidação dos compostos orgânicos, para efetuar uma redução da cor e o início da nitrificação. A nitrificação é a oxidação biológica de amônio para nitrito e a oxidação de nitrito para nitrato, realizada por bactérias especializadas, que desenvolvem atividades bioquímicas em presença de oxigênio dissolvido; estes sistemas também têm capacidade de quebrar compostos orgânicos mais resistentes. Para sua boa operação eles requerem um tempo de retenção celular (idade de lodo) alto para conseguir uma atividade biológica que inicie a nitrificação o que faria possível o controle da toxicidade, alcançando uma alta redução na DQO e cor, alcançando um alto grau de estabilização do lodo. Entre as vantagens, o sistema é adequado para áreas de espaço limitado com versatilidade de operação; permite variações na carga orgânica, na aeração e nas mudanças dos tempos e ciclos. O sistema é o mais adequado para zonas urbanas com limitação de área ou indústrias com áreas pequenas. Como recomendação no tratamento, os efluentes devem ser neutralizados e suplementados com nutrientes como uréia $(N)$ e acido fosfórico $(P)$; por exemplo, adicionaram ao despejo nitrogênio e fósforo como nutrientes na relação:

$$
\text { DBO: } N: P=100: 5: 1
$$

Então, como objetivo geral do trabalho se elaborou a montagem de um reator de laboratório (inocular) para tratamento biológico deste efluente têxtil no sistema de Lodos Ativados por Batelada (LAB) de 40 L, e avaliou-se a sua eficiência nos parâmetros: Cor ADMI, DQO (demanda química de oxigênio), COD (carbono orgânico dissolvido) e Serie de Sólidos; sendo importante o desenvolvimento de uma metodologia apropriada para estes efluentes industriais com elevados valores de Cor, demanda de oxigênio, carbono dissolvido e variabilidade de sólidos (suspensos e dissolvidos).

\section{MATERIAIS E MÉTODOS}

\section{A. Investigação Experimental}

O trabalho de investigação preparou e avaliou o des- empenho, em escala de laboratório, de um reator no sistema de Lodos Ativados por Batelada (LAB) de $40 \mathrm{~L}$ de capacidade, no tratamento de efluente de indústria têxtil. Os despejos usados no laboratório para montar o reator, foram provenientes de uma indústria têxtil da região de Americana, no Estado de São Paulo, que realiza as operações de tecelagem, preparação, tingimento, estampagem e acabamento. $\mathrm{Na}$ investigação, avaliou-se a eficiência do sistema: quanto à estabilidade do reator, no parâmetro de quantidade de sólidos, o seja os SST (sólidos suspensos totais da Serie de Sólidos) em valores estáveis no transcurso da o tratamento; e quanto a avaliação de eficiência do tratamento de despejos, nos parâmetros Cor ADMI, Demanda Química de Oxigênio (DQO) e Carbono Orgânico Dissolvido (COD), além de pH e temperatura.

O efluente foi coletado diretamente no tanque de equalização na industria; e armazenado nos laboratórios da UNICAMP, em geladeira à temperatura inferior a 4 oC; colocado à temperatura ambiente 24 horas antes de ser usado. Eram corrigidos o pH e adicionado nutrientes, no efluente bruto, no final de cada semana, para ser usado na semana seguinte.

Os nutrientes, uréia com $47 \%$ de nitrogênio (N) e ácido fosfórico com $32 \%$ de fósforo $(\mathrm{P})$, foram adicionados com base no valor adotado de $\mathrm{DBO} 5,20$ no Efluente Bruto (EB) de $900 \mathrm{mg}$ de O2/L. Considerouse uma relação para adição de nutrientes de $\mathrm{DBO} 5,20$ : $\mathrm{N}$ : P em $100: 5$ : 1 (BRESAOLA \& CANTELLI, 2001; PÔRTO,2002), e para cada 20 litros foram adicionados 1,92 g. de uréia e 0,4 mL de ácido fosfórico.

A correção do $\mathrm{pH}$ foi feita com uma solução de barrilha a $50 \mathrm{mg} / \mathrm{L}$ ou com uma solução de ácido clorídrico. Definiu-se a faixa de correção de $\mathrm{pH}$ entre 7,0 e 8,0 . Foram mantidas no reator biológico as seguintes condições operacionais:

O reator funcionou sete dias na semana; as trocas de efluente tratado por efluente bruto eram feitas de segunda a sábado; no ultimo dia (domingo) o reator 
permanecia só em movimentação e aeração; a aeração e mistura do reator foram obtidas através de 5 bombas de mistura e difusão de ar e pedras porosas (bombas tipo aquário caseiro); o reator funcionou com fluxo intermitente ou batelada, em ciclos de 24 horas (na Figura 1 mostram-se as operações diárias efetuadas no reator biológico); nos ciclos fizeram-se as operações de enchimento (feito de forma quase instantânea), reação (22 horas), sedimentação (1,5 hora) e esvaziamento em repouso (0,5 hora); retirou-se diariamente uma fração correspondente a $1 / 20$ (2 L) da capacidade do reator, com a mistura em movimentação para garantir um tempo de residência celular (idade de lodo) de 23,3 dias; para manter a fração de lodo de $50 \%$ na operação de esvaziamento retiravam-se $18 \mathrm{~L}$ de efluente tratado do reator (para um total de $20 \mathrm{~L}$ ); o descarte do efluente tratado e o esvaziamento foram feitos por meio de

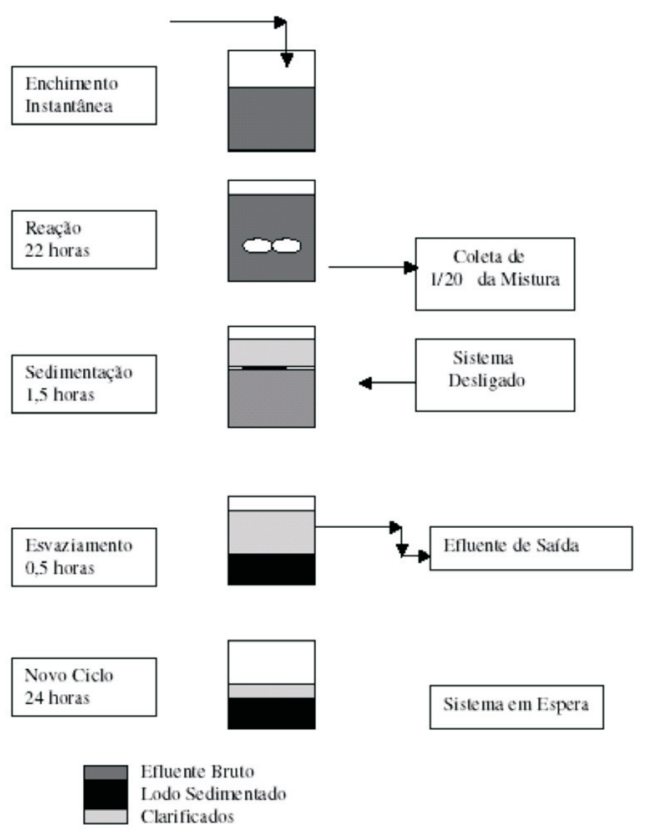

Figura 1. Operações Efetuadas nos Reatores Biológicos. Fonte: PÔRTO,2002 válvulas hidráulicas colocadas no reator; no enchimento do reator usou-se um tanque de 20 litros de capacidade que alimentava por gravidade o reator.

Para o trabalho experimental, foram realizadas as seguintes atividades: Deu-se partida ao reator, inoculando-o com mistura em suspensão de "lodo biológico de tratamento de esgoto e de efluente têxtil" de estudos de bancada no laboratório; o despejo foi condicionado com nutrientes e corrigido nos valores de $\mathrm{pH}$ conforme descrito na metodologia; mediu-se diariamente a temperatura e $\mathrm{pH}$ no reator e caracterizou-se as amostras do EB (efluente bruto) e ET (efluente tratado) com os parâmetros Cor ADMI, DQO e COD e Série de Sólidos e operou-se até atingir o estado de equilíbrio, caracterizado pelas variações mínimas na eficiência de remoção destes parâmetros, ou pela pouca variação de sólidos em suspensão no interior do reator.

\section{B. Partida do Reator Biológico}

Durante duas semanas foi adicionada, $200 \mathrm{~mL}$, da mistura em suspensão, onde a capacidade de tratamento do reator foi aumentada gradativamente até atingir o valor desejado de 40 litros após três semanas. A operação das três semanas iniciais nos processos de enchimento, sedimentação e descarte do efluente no reator foi feita segundo o plano mostrado na Tabela 1.

Após a terceira semana de funcionamento o reator entrou na fase de troca normal diária, ou seja, descarte de 2 litros de mistura ( $1 / 20$ do total da capacidade do tratamento do reator), sedimentação, descarte de 18 litros de efluente tratado e o enchimento de 20 litros de EB. Operação continua até entrar na fase de equilíbrio. 
Tabela 1. Inicio do Reator Biológico

\begin{tabular}{|c|c|c|c|c|c|c|c|}
\hline Semana & Dia & $\begin{array}{l}\text { Substrato } \\
\text { inicial } \\
\text { (L ) }\end{array}$ & $\begin{array}{c}\text { Descarte } \\
\text { mistura } \\
-(\mathrm{L})\end{array}$ & $\begin{array}{c}\text { Descarte } \\
\text { tratado } \\
-(L)\end{array}$ & $\begin{array}{c}\text { Bio } \\
\text { mistura } \\
+(\mathrm{L})\end{array}$ & $\begin{array}{c}\text { Efluente } \\
\text { bruto } \\
+(\mathrm{L})\end{array}$ & $\begin{array}{c}\text { total } \\
\text { enchimento } \\
+(\mathrm{L})\end{array}$ \\
\hline \multirow[t]{7}{*}{1} & 1 & 0,0 & 0,0 & 0,0 & 0,2 & 5,0 & 5,2 \\
\hline & 2 & 5,2 & 0,0 & 2,6 & 0,2 & 5,0 & 7,8 \\
\hline & 3 & 7,8 & 0,0 & 3,9 & 0,2 & 5,0 & 9,1 \\
\hline & 4 & 9,1 & 0,0 & 4,6 & 0,2 & 5,0 & 9,8 \\
\hline & 5 & 9,8 & 0,0 & 4,9 & 0,2 & 5,0 & 10,1 \\
\hline & 6 & 10,1 & 0,0 & 5,0 & 0,2 & 10,0 & 15,2 \\
\hline & 7 & 15,2 & 0,0 & 7,6 & 0,2 & 10,0 & 17,8 \\
\hline \multirow[t]{7}{*}{2} & 8 & 17,8 & 0,0 & 8,9 & 0,2 & 10,0 & 19,1 \\
\hline & 9 & 19,1 & 0,0 & 9,6 & 0,2 & 10,0 & 19,8 \\
\hline & 10 & 19,8 & 0,0 & 9,9 & 0,2 & 10,0 & 20,1 \\
\hline & 11 & 20,1 & 0,0 & 10,0 & 0,2 & 20,0 & 30,2 \\
\hline & 12 & 30,2 & 0,0 & 15,1 & 0,2 & 20,0 & 35,3 \\
\hline & 13 & 35,3 & 0,0 & 17,7 & 0,2 & 20,0 & 37,9 \\
\hline & 14 & 37,9 & 0,0 & 18,9 & 0,2 & 20,0 & 39,1 \\
\hline \multirow[t]{7}{*}{3} & 15 & 39,1 & 2,0 & 17,1 & 0,0 & 20,0 & 40,0 \\
\hline & 16 & 40,0 & 2,0 & 18,0 & 0,0 & 20,0 & 40,0 \\
\hline & 17 & 40,0 & 2,0 & 18,0 & 0,0 & 20,0 & 40,0 \\
\hline & 18 & 40,0 & 2,0 & 18,0 & 0,0 & 20,0 & 40,0 \\
\hline & 19 & 40,0 & 2,0 & 18,0 & 0,0 & 20,0 & 40,0 \\
\hline & 20 & 40,0 & 2,0 & 18,0 & 0,0 & 20,0 & 40,0 \\
\hline & 21 & 40,0 & 2,0 & 18,0 & 0,0 & 20,0 & 40,0 \\
\hline
\end{tabular}

Após a terceira semana de funcionamento o reator entrou na fase de troca normal diária, ou seja, descarte de 2 litros de mistura ( $1 / 20$ do total da capacidade do tratamento do reator), sedimentação, descarte de 18 litros de efluente tratado e o enchimento de 20 litros de EB. Operação continua até entrar na fase de equilíbrio.

\section{Caracterização do Efluente Bruto}

Das coletas primeiro de $400 \mathrm{~L}$, após uma semana de $300 \mathrm{~L}$, e uma semana depois outra de $300 \mathrm{~L}$, tomouse, aleatoriamente, um litro de cada para análises de laboratório num lapso não maior de 48 horas da coleta. Na Tabela 2 são mostrados os resultados da ca- racterização feita nos despejos brutos coletados com relação aos parâmetros pH, Cor ADMI, DQO e COD.

Os valores encontrados nos parâmetros foram bastante variáveis entre as coletas efetuadas; por serem os processos de beneficiamento têxtil realizados em bateladas é muito difícil considerar uma correlação destes diferentes parâmetros, dificultando o tratamento. Os referenciados na bibliografia, também encontram-se nesta faixa de variabilidade. Comparado com alguns efluentes brutos da industria têxtil, o despejo apresenta um valor de Cor alta.

Os resultados quanto a Séries de Sólidos para as coletas de EB são mostradas na Tabela 3. 


Coleta Quant.
\begin{tabular}{|c||c|c|c|c|c|c|c|c|}
\hline $\begin{array}{c}\text { Coleta } \\
\text { No }\end{array}$ & Litros & media & media & Abs & mg/l & CTD & CID & COD \\
\hline 1 & 400 & 11,0 & 740 & 0,940 & 2436 & 503,0 & 98,0 & 405,0 \\
\hline 2 & 300 & 6,3 & 910 & 1,060 & 2753 & 502,0 & 99,9 & 402,1 \\
\hline 3 & 300 & 7,5 & 870 & 0,950 & 2463 & 499,0 & 10,1 & 488,9 \\
\hline
\end{tabular}

Tabela 3. Resultados da Séries de Sólidos para EB ( $\mathrm{mg} / \mathrm{L})$

\begin{tabular}{|c|c|c|c|c|c|c|c|c|c|}
\hline Coleta & ST & STF & STV & SST & SSF & SSV & SDT & SDF & SDV \\
\hline 1 & 2660 & 1977 & 683 & 269 & 215 & 54 & 2391 & 1762 & 629 \\
\hline 2 & 2520 & 1569 & 951 & 280 & 224 & 56 & 2240 & 1345 & 895 \\
\hline 3 & 2300 & 1405 & 895 & 206 & 165 & 41 & 2094 & 1240 & 854 \\
\hline
\end{tabular}

\section{Fases do Tratamento de Efluentes}

O reator operou de forma contínua; no primeiro mês, em três semanas, ele foi inoculado (início de operações) e no segundo mês esperou-se até alcançar certo equilíbrio para SST da mistura.

Recolheram-se amostras, quase diariamente, para a determinação dos valores de $\mathrm{pH}$ e temperatura do reator e semanalmente para a determinação dos valores de Sólidos Sedimentáveis (SS). A tabela 4 mostra os dados de operação de alguns dias do reator referente a estes parâmetros avaliados na mistura (dados obtidos ao final do período de reação).

Pode-se observar o crescimento dos Sólidos Sedimentáveis desde o início das operações até uma estabilização quase no final do período onde o reator atinge o valor de equilíbrio de, aproximadamente, $150 \mathrm{~mL} / \mathrm{L}$ de sólidos sedimentáveis presentes na mistura.

A estabilização dos valores nos sólidos também se apresenta nos SST da mistura do reator, incremen-
Tabela 4. Operação Diária do Reator

\begin{tabular}{|c|c|c|c|}
\hline $\begin{array}{c}\text { Teste } \\
\text { Dia }\end{array}$ & $\begin{array}{c}\text { TEMP } \\
\text { o C }\end{array}$ & $\mathbf{p H}$ & $\begin{array}{c}\text { SS } \\
\mathbf{m L} / \mathbf{L}\end{array}$ \\
\hline 1 & 23,0 & 7,3 & 60 \\
\hline 9 & 24,0 & 7,7 & 65 \\
\hline 14 & 23,0 & 7,3 & 75 \\
\hline 22 & 24,0 & 8,3 & 80 \\
\hline 27 & 22,0 & 7,8 & 85 \\
\hline 29 & 22,5 & 7,8 & 90 \\
\hline 38 & 22,0 & 7,4 & 95 \\
\hline 39 & 22,0 & 7,4 & 100 \\
\hline 50 & 22,0 & 7,9 & 110 \\
\hline 53 & 23,0 & 7,6 & 120 \\
\hline 66 & 21,0 & 8,2 & 130 \\
\hline 69 & 22,0 & 8,3 & 135 \\
\hline 74 & 21,0 & 7,9 & 140 \\
\hline 77 & 22,0 & 7,8 & 150 \\
\hline 81 & 23,0 & 8,3 & 150 \\
\hline 84 & 22,0 & 7,6 & 150 \\
\hline Equilíbrio & & & \\
\hline
\end{tabular}

tando-se de dados inferiores a $300 \mathrm{mg} / \mathrm{L}$ até valores acima ou próximos a $3000 \mathrm{mg} / \mathrm{L}$ ao final do segundo mês do inicio das operações. Os resultados mostraram eficiência do tratamento do despejo bruto, no reator, para Cor ADMI superiores a 70\%, DQO valores 
superiores a $65 \%$, e COD perto do $70 \%$.

Apos a operação do tratamento num volume estabelecido por batelada, na quantidade de EB, lodo resultante e ET, logro-se uma idade do lodo $\left(\theta_{c}\right)$ de 23 dias e ciclos de 24 horas.

Os SST para o efluente tratado no reator diminuíram até um valor de equilíbrio aproximado de $250 \mathrm{mg} / \mathrm{L}$. Pode-se inferir que as quantificações de sólidos não atingidos pela sedimentação incorporam muitas partículas suspensas pouco sedimentáveis e também aquelas que por efeito das bolhas do ar tendem a ficar no sobrenadante no tempo de sedimentação.

\section{CONCLUSÕES E RECOMENDAÇÕES}

Nas considerações do tratamento de efluente no reator biológico e conforme a experimentação, conclui-se que este, após o inicio das operações (com inoculo ou semente de outros reatores que tratavam esgoto domestico ou efluente têxtil sem adição de coagulantes, CAP u outros floculadores químicos) e logo após três semanas adicionando-se despejo têxtil bruto, ele operou por um tempo até atingir uma estabilidade funcional.

Os valores de $\mathrm{pH}$, no reator, após tempo de reação, variaram na faixa de 7,5 até 8,0; sendo que o despejo bruto tinha sido ajustados na faixa de pH entre 7,0 e 8,0.

Com idade do lodo $\left(\theta_{c}\right)$ de 23 dias e ciclos de 24 horas, pode-se concluir que:

- Os valores de SS, na mistura do reator após tempo de reação, ficaram perto de $150 \mathrm{~mL} / \mathrm{L}$; alguns testes de SS feitos, para efluentes tratados, indicaram sólidos sedimentáveis inferiores a $1 \mathrm{~mL} / \mathrm{L}$.

- Os valores dos SST das misturas no reator ficaram com valores perto de $3.000 \mathrm{mg} / \mathrm{L}$; a faixa de valores para efluentes tratados, ficou entre $250 \mathrm{mg} / \mathrm{L}$ e 350 $\mathrm{mg} / \mathrm{L}$; algumas avaliações foram feitas para os lodos resultando valores de teor de sólidos perto de $4 \%$.

-Para o reator, a eficiência de remoção de Cor ADMI no efluente ficou na faixa de 60 a $70 \%$. Para a DQO, a eficiência de remoção foi de 70 a $75 \%$. Os resultados na eficiência de remoção de COD, na faixa de 65 a $75 \%$.

Como estes efluentes em geral, caracterizam-se pela grande variabilidade da carga orgânica, elevada concentração de sais dissolvidos, presença de compostos orgânicos lentamente biodegradáveis, cor elevada e alta concentração de detergentes, podendo apresentar toxicidade e mutagenicidade, o tratamento biológico aeróbio, para estes casos, tem acogida e é bastante empregado na prática, mas recomendase, na maioria da vezes, avaliar as características do efluente bruto para sua possível aplicação.

\section{REFERÊNCIAS}

[1]. BRESAOLA, R. \& CANTELLI, D.L., (2001). "Tratamento de Efluentes Líquidos de uma Industria Têxtil e seu Réus", $27^{\circ}$ Congresso Interamericano de Engenharia Sanitária e Ambiental. Brasil.

[2]. FERREIRE da SILVA, A, (2004). "Preparação, caracterização e aplicação de membranas de poli (fluoreto de vinil) para a redução de cor de Efluente Têxtil modelo.", Dissertação de Mestrado, Engenharia Química, Unicamp, Brasil.

[3]. FUKUnAGA, M. T., (2003). "Estudo da degradação de efluentes aquosos derivados da industria produtora de fenol através de eletrolise foto-assistida.", Tese de Doutorado, Engenharia Mecânica, Unicamp. Brasil.

[4]. HELMREICH, B; SCHREFF, D; WILDERER, P., (2000). "Full scale experiences with small sequencing batch reactor plants in Bavaria". Water Science and Technology, v.41, n.1, p. 89-96. 
[5]. NETO, H. G. \& SILVA, E. L., (2005). “Cinética do consumo anaeróbio de fenol em reator operando em batelada", $\mathrm{VI}^{\circ}$ Congresso Brasileiro de Engenharia Química. Brasil.

[6]. PORTO, L., (2002). "Tratamento de Efluente Têxtil em Sistemas de Lodos Ativados de Fluxo Intermitente com a Adição de Carvão Ativado em Pó.". Dissertação de Mestrado, Engenharia Civil, Unicamp, Brasil.

[7]. SALES, P; OLIVEIRA, M;KYIOMI, P;DUTRA, R; GOMES, W; BRITO,N; BARBOSA, A; SILVA, C; FIORENTINO, J; LOPES, T; PELEGRINI, R., (2003). "Tratamento de corante dispersivo por processo fotocatalítico com TiO2". Faculdades Integradas Claretianas, III Fórum de Estudos Contábeis, Rio Claro, São Paulo, Brasil,

[8]. SOUZA, T.C., FERREIRA, C. A., BRANDAO, P.C., HORI, E. C., ROMANIELO, L. L., (2005). "Avaliação do uso de biomassa como adsorvente para a separação de contaminantes orgânicos em efluentes líquidos" VI Congresso Brasileiro de Engenharia Química, Brasil.

[9]. USEPA (United States Environmental Protection Agency): "Profile of the Textile Industry", Office of Compliance Sector Notebook Project, Washington, DC, EUA, 1997.

[10]. YAMUGUTI,C. E., SOTTORIVA, P., SILVA, F. T., PAIVA, T. C.: "Remediação de efluentes da industria têxtil utilizando processo fotoquímico UV/H2O2" VI Congresso Brasileiro de Engenharia Química, 2005. 